ORIGINAL ARTICLE

\title{
The London Underground: dust and hazards to health
}

\author{
A Seaton, J Cherrie, M Dennekamp, K Donaldson, J F Hurley, C L Tran
}

Occup Environ Med 2005;62:355-362. doi: 10.1136/oem.2004.014332

See end of article for authors' affiliations .....................

Correspondence to: Emeritus Professor A Seaton, Institute of Occupational Medicine, Edinburgh, UK; a.seaton@ abdn.ac.uk

Accepted 21 October 2004

\begin{abstract}
Aims: To assess hazards associated with exposure to dust in the London Underground railway and to provide an informed opinion on the risks to workers and the travelling public of exposure to tunnel dust. Methods: Concentrations of dust, as mass $\left(\mathrm{PM}_{2.5}\right)$ and particle number, were measured at different underground stations and in train cabs; its size and composition were analysed; likely maximal exposures of staff and passengers were estimated; and in vitro toxicological testing of sample dusts in comparison with other dusts was performed.

Results: Concentrations on station platforms were $270-480 \mu \mathrm{g} / \mathrm{m}^{3} \mathrm{PM}_{2.5}$ and 14 000-29 000 particles/ $\mathrm{cm}^{3}$. Cab concentrations over a shift averaged $130-200 \mu \mathrm{g} / \mathrm{m}^{3}$ and $17000-23000$ particles $/ \mathrm{cm}^{3}$. The dust comprised by mass approximately $67 \%$ iron oxide, 1-2\% quartz, and traces of other metals, the residue being volatile matter. The finest particles are drawn underground from the surface while the coarser dust is generated by interaction of brakes, wheels, and rails. Taking account of durations of exposure, drivers and station staff would have maximum exposures of about $200 \mu \mathrm{g} / \mathrm{m}^{3}$ over eight hours; the occupational exposure standard for welding fume, as iron oxide, is $5 \mathrm{mg} / \mathrm{m}^{3}$ over an eight hour shift. Toxicology showed the dust to have cytotoxic and inflammatory potential at high doses, consistent with its composition largely of iron oxide.

Discussion: It is unjustifiable to compare $\mathrm{PM}_{2.5}$ exposure underground with that on the surface, since the adverse effects of iron oxide and combustion generated particles differ. Concentrations of ultrafine particles are lower and of coarser $\left(\mathrm{PM}_{2.5}\right)$ particles higher underground than on the surface. The concentrations underground are well below allowable workplace concentrations for iron oxide and unlikely to represent a significant cumulative risk to the health of workers or commuters.
\end{abstract}

n 1999, Pfeifer and colleagues, investigating metal concentrations in the blood of London commuters, noted higher manganese levels among those using the underground railway. ${ }^{1}$ Dust concentrations were studied in the London Underground (LU) in 2001, ${ }^{2}$ and similar results have been reported from Stockholm in 2002 and New York in $2004 .^{3}{ }^{4}$ For a decade prior to these studies it had been known that LU was a relatively dusty environment compared to conditions above ground, ${ }^{5}$ and a recent report on the worldwide web has raised the possibility that workers and even commuters may be put at risk in that environment. $^{6}$ This report attracted much media interest and understandably caused concern among the workers. A recent report by the British Lung Foundation, in suggesting that travel on the Underground may be hazardous, has uncritically quoted research as having shown that "travelling for 20 minutes on the Northern line through central London had the same effect on the lungs as smoking a cigarette" ${ }^{\prime \prime}$

After detailed discussions with representatives of management and trade unions, we were commissioned by London Underground to investigate the amount, composition, and concentration of dust to which workers and passengers are exposed and to investigate some of the toxicological characteristics of the dust. The trade union representatives nominated the sites at which the dust sampling should be carried out. It was anticipated that the information obtained would, by comparison with the results of research on other workplace dust exposures and outcomes, allow us to comment on the likely risks to the health of those exposed and to decide whether further, epidemiological, research would be desirable.

\section{DUST EXPOSURES OF EMPLOYEES AND PASSENGERS: HOW MUCH AND WHAT KIND OF DUST ARE PEOPLE EXPOSED TO? \\ Methods}

Dust measurement

Particulate matter less than $2.5 \mu \mathrm{m}$ in aerodynamic diameter $\left(\mathrm{PM}_{2.5}\right)$ was measured using a portable DustTrak light scattering monitor (TSI Inc., St Paul, Minnesota, USA), calibrated against gravimetric $\mathrm{PM}_{2.5}$ measurement of samples from the Underground (this sampler is calibrated in the factory and needs to be re-calibrated for different types of dust). The particle number concentration (PNC) was measured using a P-Trak monitor (TSI Inc.), in which particles are drawn through a saturator tube, mix with propanol vapour, and pass into a condenser tube where condensation of the propanol causes them to grow into larger droplets that can be counted by a laser beam and photodetector. This is designed to count particles from 0.02 to $1 \mu \mathrm{m}$.

Static airborne dust samples for subsequent laboratory analysis were collected by respirable dust (approximately $\mathrm{PM}_{3.5}$ ), $\mathrm{PM}_{2.5}$, and $\mathrm{PM}_{10}$ samplers. All the respirable dust samples were analysed by infrared spectroscopy to determine mass of quartz. ${ }^{8}$ The $\mathrm{PM}_{2.5}$ samples were analysed by inductively coupled plasma/atomic emission spectrometry for iron, chromium, copper, zinc, and manganese. ${ }^{9}$

Samples were collected using battery operated pumps with open face cowl holders fitted with Nuclepore polycarbonate filters at a low flow rate to analyse the particle size distribution, using a transmission electron microscope

Abbreviations: LU, London Underground; PM, particulate matter; PNC, particle number concentration 
(TEM). The particle analysis used a Link AN10000 semiautomatic system with the TEM set at $5000 \times$ magnification on a slow scan speed. For each sample, approximately 1000 particles were analysed (each mean diameter being the result of 10 individual measurements per particle). This measures actual rather than aerodynamic diameter, and therefore underestimates the aerodynamic diameter of dense, iron containing particles.

The sampling heads were located approximately $2.5 \mathrm{~m}$ above the platforms in three busy LU stations, in two cases closest to where trains entered the station (Holland Park, HP and Hampstead, H) and in one (Oxford Circus, OC) at the far end of the platform. Measurements began around $7 \mathrm{am}$ and continued until $5 \mathrm{pm}$, on three successive days. This included one of the two peaks of traffic in line with the shift patterns of workers. The flow rate of each pump based sampler was calibrated periodically during the day. Long term high volume $\mathrm{PM}_{2.5}$ samples were collected from the station platforms and the roof of the LU offices (Griffith House, $\mathrm{GH}$ ) in central London, for the toxicity studies. It was not possible to collect sufficient $\mathrm{PM}_{2.5}$ for these studies, so a $\mathrm{PM}_{10}$ sample available to us from Manchester was used in some cases.

Personal sampling in the drivers' cabs was carried out for three days on each line, using a second set of DustTrak and PTrak samplers. Both samplers were positioned inside the cab as close as possible to the driver's breathing zone, and the driver was accompanied by one of the researchers. Sampling was from the driver's booking time until the end of the shift. These measurements were continuous except for lunch breaks, which lasted 30-60 minutes, and results were adjusted to represent the whole shift.

We recorded the times when the drivers were under- and above-ground in the cab, to aid interpretation of time specific concentrations. The platform data used for comparison comprised the concentrations half an hour before and after the time when the measurements were made on the surface. Data from the DustTrak and P-Trak used inside the cabs were adjusted so that they corresponded to the platform instruments, the former of which had been adjusted to correspond to the gravimetric $\mathrm{PM}_{2.5}$ data. This adjustment was made on the basis of side-by-side comparisons of the four instruments on the station platform.

\section{Results}

Particle size distribution

Examination of the airborne tunnel dust by transmission electron microscope showed that the aerosol collected on each station platform was qualitatively similar, as illustrated in fig 1 . Many of the particles were smaller than $1 \mu \mathrm{m}$, and a proportion appeared to comprise smaller particles aggregated together. Figure 2 shows the particle size measurements from the three station platforms in the form of a histogram. The distributions from the three stations were very similar, with a median diameter around $0.4 \mu \mathrm{m}$. About $80 \%$ of the particles had a diameter less than $1 \mu \mathrm{m}$. Note that this microscopic method of measurement underestimates the aerodynamic diameter of the denser particles. The airborne dust found in cities is generally finer than this. For example, a report from the Committee on the Medical Effects of Air Pollutants quotes the median size of airborne dust from the air in London to range from 0.09 to $0.13 \mu \mathrm{m} .{ }^{10}$

\section{Particle chemistry}

The LU dust was found to comprise $64-71 \%$ iron oxide by mass in the $\mathrm{PM}_{2.5}$ samples. We detected $0.1-0.2 \%$ chromium, $0.5-1 \%$ manganese, $<0.1-0.9 \%$ copper, and no zinc in the same samples. Between $1 \%$ and $2 \%$ quartz was found in the respirable dust samples.

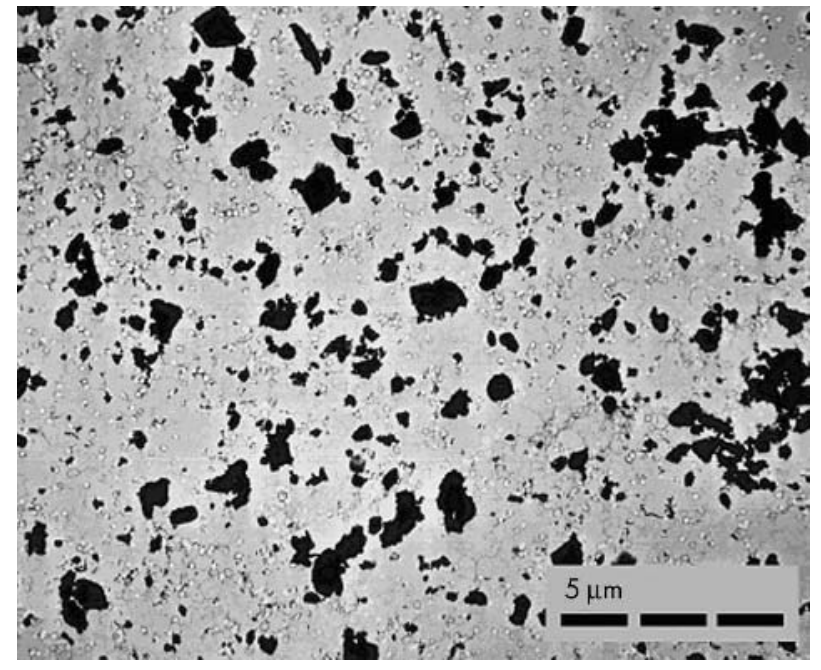

Figure 1 Photomicrograph of airborne tunnel dust from Holland Park station, showing the majority of the particles to be between 0.5 and 5 $\mu \mathrm{m}$, some of the larger ones being clumps of smaller particles.

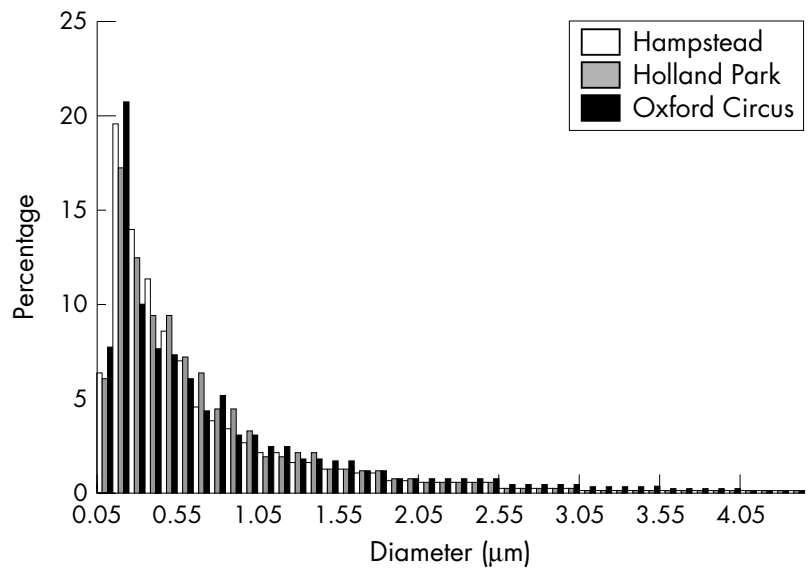

Figure 2 Particle size distributions for each station plafform, showing similar size distributions in the three stations.

\section{Concentrations on platforms}

The results at the three stations over three days are shown in table 1. Average $\mathrm{PM}_{2.5}$ concentrations ranged from $270 \mu \mathrm{g} / \mathrm{m}^{3}$ to $480 \mu \mathrm{g} / \mathrm{m}^{3}$, and corresponding particle number counts from 14000 to $29000 / \mathrm{cm}^{3}$. The lower number concentrations at Hampstead reflected lower above-ground concentrations at that site. Figure 3 shows data for a single day's sampling at Oxford Circus. The particle number concentration rose steadily from early morning until just after midday, and then remained fairly constant, in keeping with induction of outside air into the system. In contrast, the concentrations of $\mathrm{PM}_{2.5}$ reflected the pattern of rail traffic through the station.

Data from sampling on platforms are shown in table 2 . The concentrations are high compared with mass concentrations above ground. The ratio of $\mathrm{PM}_{2.5}$ to $\mathrm{PM}_{10}$ is less than 0.3 in all three stations, about half that found typically above ground, illustrating the coarser nature of underground dust.

\section{Concentrations in train cabs}

Table 3 summarises the concentrations in the cabs of the trains on the three lines over three separate days. The cab data cover the entire shift, including measurements when the train was on the surface. Average levels of $\mathrm{PM}_{2.5}$ were about 


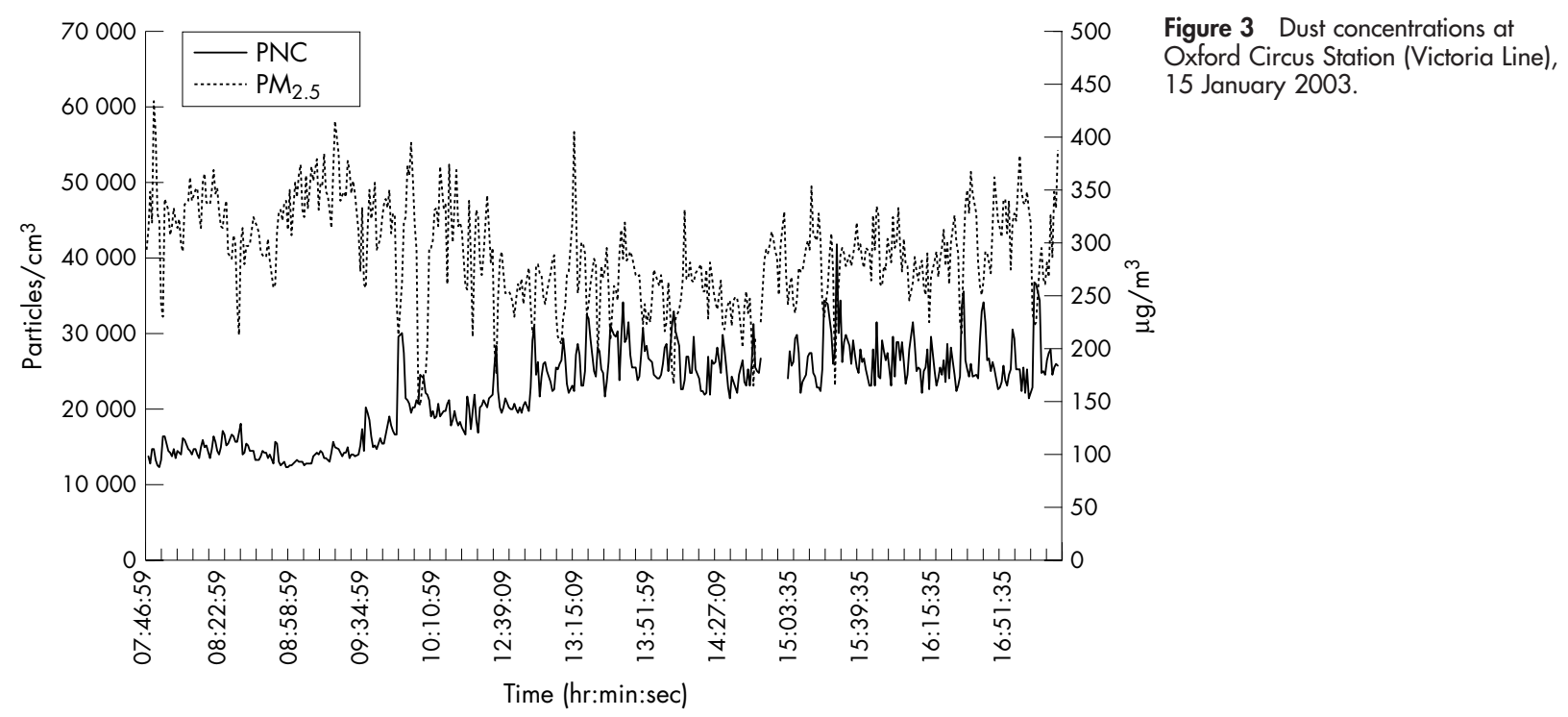

Table 1 Average dust concentrations on the platform for the three stations (three days)

\begin{tabular}{llll}
\hline Station & Location & $\begin{array}{l}\text { PM }_{2.5}\left(\mu \mathrm{g} / \mathrm{m}^{3}\right) \\
\text { Mean (SD) }\end{array}$ & $\begin{array}{l}\left.\text { PNC (particles } / \mathrm{cm}^{3}\right) \\
\text { Mean (SD) }\end{array}$ \\
\hline Holland Park Station & Central Line & $300(0)$ & $29000(6700)$ \\
Hampstead Station & Northern Line & $480(26)$ & $14000(2500)$ \\
Oxford Circus Station & Victoria Line & $270(21)$ & $24000(4500)$ \\
\hline
\end{tabular}

Table 2 Data from pump based monitoring on station platforms (three days)

\begin{tabular}{|c|c|c|c|c|}
\hline Station & Location & $\begin{array}{l}\mathrm{PM}_{2.5}\left(\mu \mathrm{g} / \mathrm{m}^{3}\right) \\
\text { Mean (SD) }\end{array}$ & $\begin{array}{l}\text { Respirable } \\
\left(\mu \mathrm{g} / \mathrm{m}^{3}\right) \\
\text { Mean (SD) }\end{array}$ & $\begin{array}{l}\mathrm{PM}_{10}\left(\mu \mathrm{g} / \mathrm{m}^{3}\right. \\
\text { Mean (SD) }\end{array}$ \\
\hline Holland Park & Central Line & $310(17)$ & 790 (37) & $1000(160)$ \\
\hline Hampstead & Northern Line & 420 (14) & 1400 (47) & 1500 (120) \\
\hline Oxford Circus* & Victoria Line & 300 (18) & 920 (63) & 1100 (33) \\
\hline
\end{tabular}

*Two $\mathrm{PM}_{10}$ measurements excluded because of errors in sampling/analysis.

one half of those measured on platforms (table 1), whereas the average PNCs were similar to those on platforms. The differences between the lines represent different durations spent underground.

Figure 4 shows continuous data for dust concentrations over a whole shift in the cab of a train travelling on the Central line. Mass concentrations were increased when the train was in tunnels. Number concentrations also showed increases at similar times (correlation 0.43), because the underground sections of the journey are in more polluted central London, where numbers reflect higher above-ground concentrations. It can be seen that when above ground, the

Table 3 Mean concentration of $\mathrm{PM}_{2.5}$ and PNC in drivers' cabs

\begin{tabular}{|c|c|c|}
\hline Location & $\begin{array}{l}\mathrm{PM}_{2.5}\left(\mu \mathrm{g} / \mathrm{m}^{3}\right) \\
\text { Mean (SD) }\end{array}$ & $\begin{array}{l}\text { PNC (particles } / \mathrm{cm}^{3} \text { ) } \\
\text { Mean (SD) }\end{array}$ \\
\hline Central Line & $130(12)$ & $23000(3500)$ \\
\hline Northern Line & 200 (1) & 17000 (1700) \\
\hline Victoria Line & 180 (13) & $22000(5000)$ \\
\hline
\end{tabular}

number concentrations are relatively higher than the mass concentrations and vice versa, again in keeping with induction of ultrafine particles from outside.

\section{Comparisons with above ground}

Measurements on the platform and on the surface, made on one day at Hampstead and all three days at Oxford Circus, showed higher number counts and lower gravimetric concentrations on the surface than underground (table 4).

\section{Estimates of exposures underground}

For the drivers the measurement data directly represent their exposures, since they were collected inside the cab for the most of the shift. The best available information for station staff was that the maximum amount of time spent on the platform was c5 hours. Their exposure estimates are therefore based on a time weighted average of the concentration measured on the platform and estimates for the surface concentration. Table 5 shows the estimated average personal exposure levels for both at the three stations/lines investigated.

We believe that these data are representative of the range of possible conditions in the system as a whole and so provide 


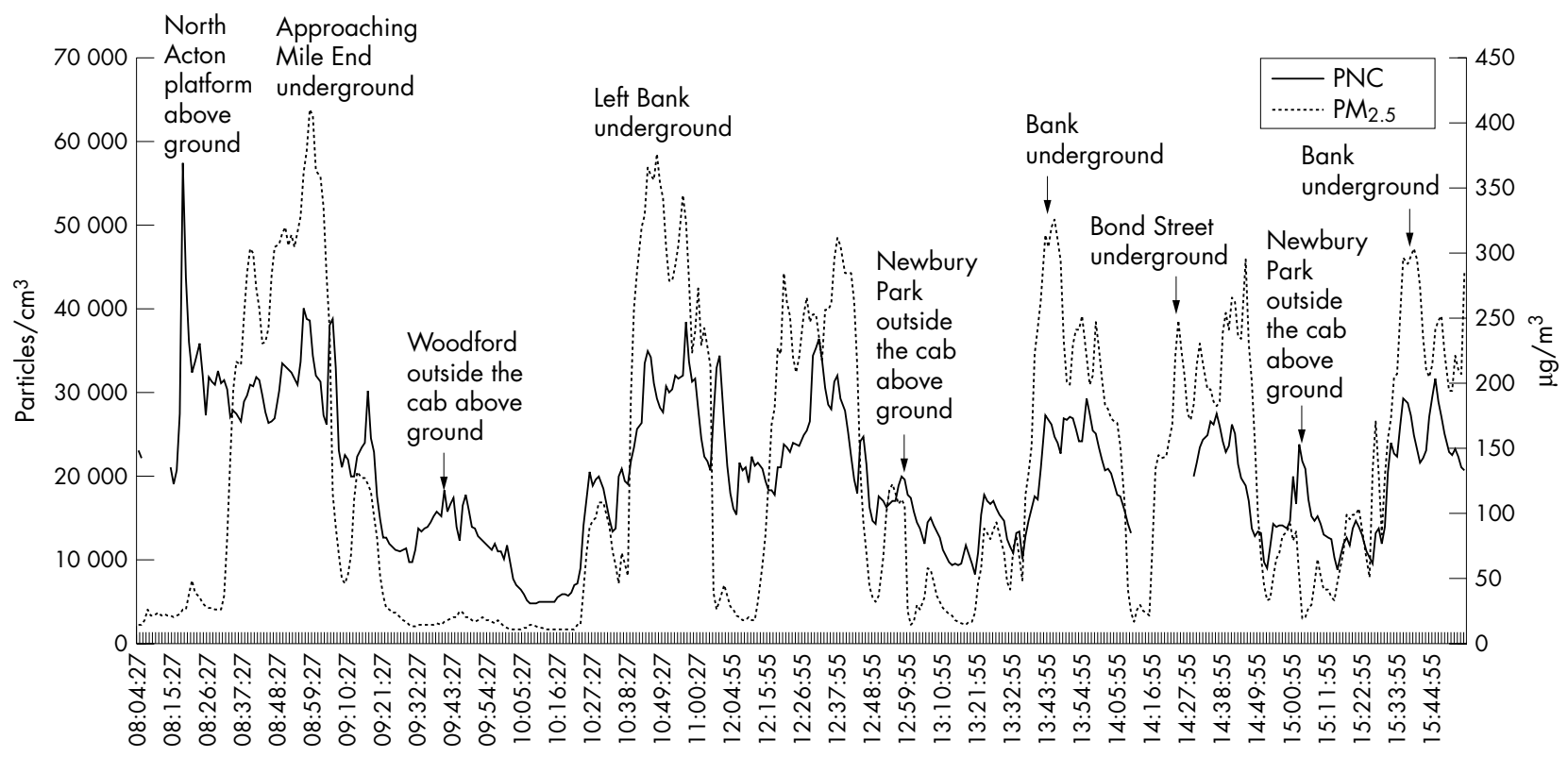

Figure 4 Continuous recording of particle number and $\mathrm{PM}_{2.5}$ concentrations in a cab over a full shift.

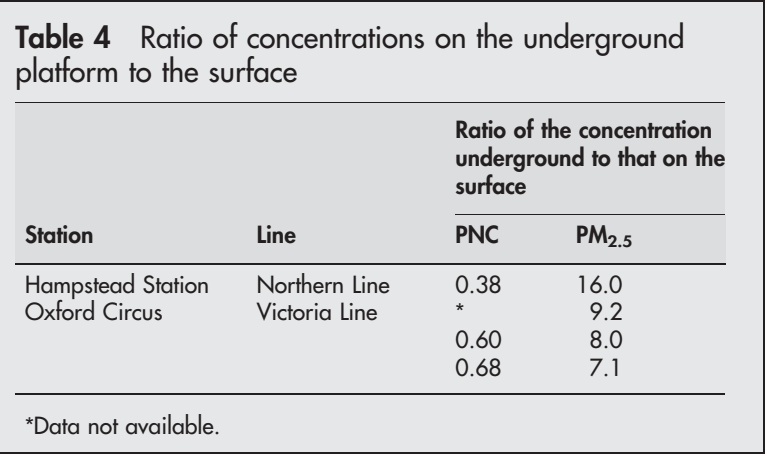

a sensible basis for exposure estimation. However, in order to allow for the possibility of higher exposures we have used the highest mean exposure plus two standard deviations from both the station and cab measurements. For drivers this highest likely exposure would correspond to $210 \mu \mathrm{g} / \mathrm{m}^{3}$ and for station staff $190 \mu \mathrm{g} / \mathrm{m}^{3}$, assuming the latter spent up to $63 \%$ of their time on the platform. Averaged over 24 hours, these correspond to an additional exposure of $60-70 \mu \mathrm{g} / \mathrm{m}^{3}$.

The exposure of commuters would be less than those of staff, since their duration of exposure underground is much less. Spending approximately 2 hours in trains or on station platforms per day with average exposure level similar to drivers-say, at most, $200 \mu \mathrm{g} / \mathrm{m}^{3}$-would increase 24 hour average exposure by $17 \mu \mathrm{g} / \mathrm{m}^{3}$. We did not consider using the PNCs for risk assessment since these represent diluted aboveground sources.

\section{TOXICOLOGY OF DUSTS: WHAT ARE THE TOXIC EFFECTS OF THE EXPOSURE? Methods}

\section{Particle samples}

Particles were retrieved from the filters by sonication in either phosphate buffered saline (PBS) or into distilled $\mathrm{H}_{2} \mathrm{O}$. The optical densities of these particles in solution were determined spectrophotometrically at an absorbance of $340 \mathrm{~nm}$ and the concentration obtained from a carbon black standard curve. Samples sonicated in PBS were used for cell exposure, whereas those sonicated in $\mathrm{dH}_{2} \mathrm{O}$ were used in the cell-free plasmid assay.

There was only sufficient $\mathrm{PM}_{2.5}$ from London for limited toxicology (IL-8). We therefore also used $\mathrm{PM}_{10}$ from Manchester that was available to us for another study and that had been collected on a tapered element oscillating microbalance (TEOM) filter. Other samples were collected from the station platforms as described in the previous section. Particle size data were obtained for a sample of titanium dioxide and a sample of welding fume that have been used as control dusts in a number of toxicity assays. The measurements were made using the methods described in the first section.

\section{Cellular toxicology}

Three standard toxicological tests were performed using the alveolar epithelial cell line A549. ${ }^{11}$ Epithelial cells were chosen because particles deposit onto these cells and they are known to be involved in the pathological responses to dusts. ${ }^{12}$ We determined the effect of the dusts on lactate

Table 5 Estimates of average personal exposure of LU staff to airborne particles

\begin{tabular}{lcllll}
\hline & \multicolumn{2}{l}{ Station staff } & & Drivers \\
\cline { 2 - 3 } Station/Line & $\begin{array}{l}\mathrm{PM}_{2.5} \\
\left(\mu \mathrm{g} / \mathrm{m}^{3}\right)\end{array}$ & $\begin{array}{l}\mathrm{PNC} \\
\left(\text { particles } / \mathrm{cm}^{3}\right)\end{array}$ & & $\begin{array}{l}\mathrm{PM}_{2.5} \\
\left(\mu \mathrm{g} / \mathrm{m}^{3}\right)\end{array}$ & $\begin{array}{l}\mathrm{PNC} \\
\left(\text { particles } / \mathrm{cm}^{3}\right)\end{array}$ \\
\hline Holland Park/Central & 75 & 29000 & 130 & 23000 \\
Hampstead/Northern & 90 & 14000 & 200 & 17000 \\
Oxford Circus/Victoria & 170 & 24000 & 180 & 22000 \\
\hline
\end{tabular}


dehydrogenase (LDH) release as a measure of cytotoxicity and on interleukin-8 protein release (IL-8) for pro-inflammatory potential. We used a cell-free assay of plasmid DNA scission as a measure of the ability of the particles to generate free radicals. ${ }^{13}$

\section{A549 cell culture and treatments}

Type II human alveolar-like epithelial A549 cells obtained from the European Type Culture Collection were grown conventionally in Dulbecco's Modified Eagle Medium at $37^{\circ} \mathrm{C}$. Cells were exposed to LU particles, $\mathrm{PM}_{10}, \mathrm{TiO}_{2}(100 \mu \mathrm{g} / \mathrm{ml})$, or DQ12 quartz over a range of doses $(1-100 \mu \mathrm{g} / \mathrm{ml})$ for eight hours for IL- 8 protein release into the supernatant or 24 hours for LDH release. Culture media from these stimulated cells were collected and analysed for IL-8 and LDH. ${ }^{14}{ }^{15}$

\section{Cell-free assay of hydroxyl radical generation}

This assay was used as previously described where plasmid DNA (PsiX174) was incubated with various concentrations of particles in a final volume of $20 \mu \mathrm{l}$ at $37^{\circ} \mathrm{C}$ for eight hours with shaking. ${ }^{16}$ The amount of free radical activity of a sample is reported as the percentage of DNA damage produced.

\section{Results}

Cytotoxicity

Sample GH denotes a $\mathrm{PM}_{2.5}$ sample collected in a background site near the LU offices as a control. In fig 5 and subsequently, the tunnel dusts are labelled as HP (Holland Park), H (Hampstead), and OC (Oxford Circus). Figure 5 shows that all three tunnel dusts could cause death to epithelial cells as measured by release of LDH. At the highest dose, HP caused about $17 \%$ of the total releasable $\mathrm{LDH}$ to be freed. The negative control $\mathrm{TiO}_{2}$ caused about $2 \%$ release of $\mathrm{LDH}$ at the highest dose and $\mathrm{PM}_{10}$ (from Manchester) caused about 7\% LDH release at the highest dose. The relevance of cytotoxicity seen at this high dose is discussed below.

\section{Interleukin-8}

The release of IL- 8 protein in response to treatment with various particles is shown in fig 6 . The error bars are very small and are lost within the symbols. There was a dose dependent stimulation of IL-8 with all of the tunnel dusts. The $\mathrm{PM}_{2.5}$ from a control site produced much less stimulation than the tunnel dusts at the highest dose, and $\mathrm{TiO}_{2}$ was the least active in causing IL-8 release at the highest dose.

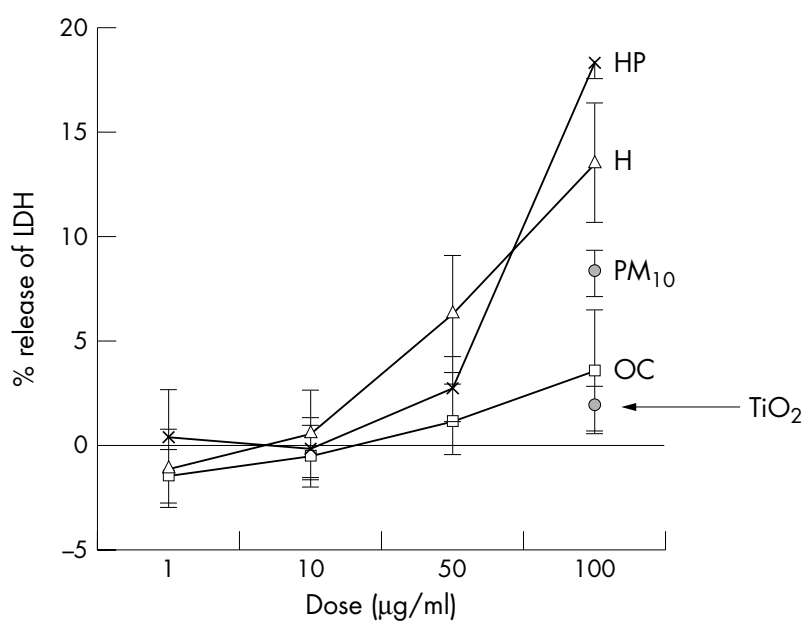

Figure 5 Percentage of total $L D H$ released by cells treated with various doses of different particles. Data are mean (SEM) of triplicate wells in three separate experiments.

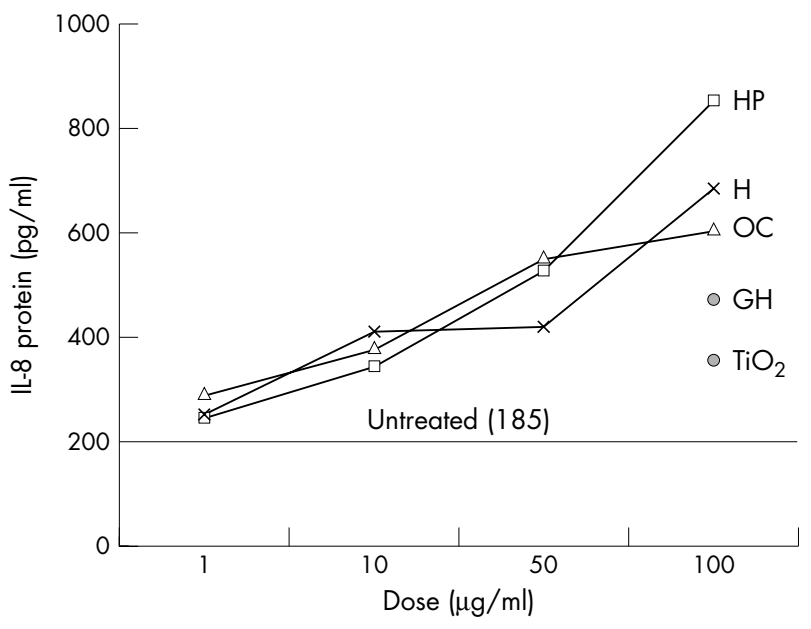

Figure 6 IL-8 release induced by various doses of the different particles. Data presented are mean (SEM) of triplicate wells in three separate experiments.

Role of soluble transition metals in the IL- 8 releasing activity of the tunnel dusts

The control IL-8 levels were rather higher than in the experiments reported in fig 6, and the amount of stimulation by the soluble components was between 400 and $500 \mathrm{pg} / \mathrm{ml}$ about half of that produced by the whole particles (particles + soluble components). Production of IL-8 by the soluble components of tunnel dust was decreased to less than control values by chelation (fig 6), indicating that all of the IL-8 stimulating activity in the supernatants could be explained by soluble transition metals. This compares with similar reduction in the IL-8 releasing activity of the soluble components of welding fume when they are treated with chelex beads. ${ }^{15}$ Chelation had little effect on control medium or soluble components of $\mathrm{PM}_{10}$ (fig 6).

Plasmid assay

The plasmid assay revealed the tunnel dusts to have more free radical activity than $\mathrm{TiO}_{2}$ and $\mathrm{PM}_{10}$, which had activity that was no different from controls (fig 7).

\section{Benchmarking against other dusts}

In order to place the toxicity of the tunnel dusts in context we have chosen quartz and welding fume data available from recent and ongoing studies for comparison. Figures 8 and 9 show the data obtained in the present study for tunnel dust

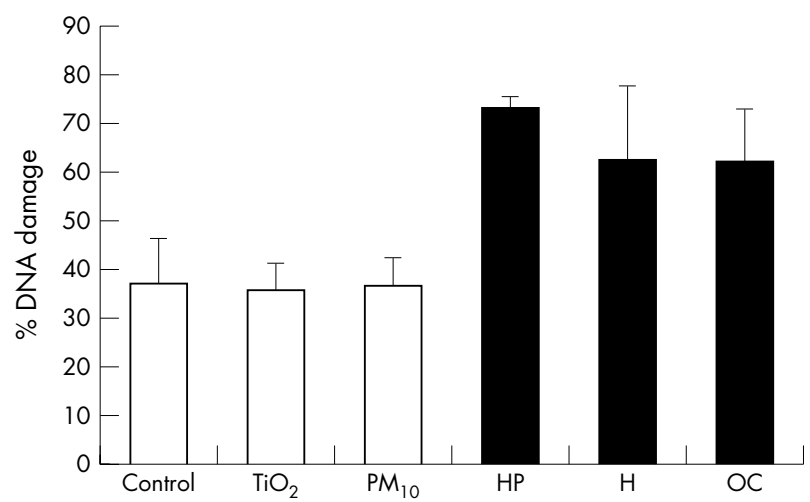

Figure 7 Amount of plasmid DNA damage caused by various particle types. Data represent the mean of duplicate lanes in three separate experiments. 
(the average of the three stations) and $\mathrm{TiO}_{2}$ plus data from other studies for quartz and welding fume. None of these experiments used $100 \mu \mathrm{g} / \mathrm{ml}$ and so the closest dose used (80 or $125 \mu \mathrm{g} / \mathrm{ml}$ ) is shown; all data represent the mean from three separate experiments. Figures 8 and 9 show that quartz was highly lethal but stimulatory at low dose, while $\mathrm{TiO}_{2}$ was low in activity. Tunnel dust and welding fume in the two assays are similar in activity and much closer to $\mathrm{TiO}_{2}$ than to quartz in activity. Figure 10 shows the comparative size distributions of these dusts. The median size of the welding fume measured by electron microscopy was $0.2 \mu \mathrm{m}$ (90\% less than $0.7 \mu \mathrm{m})$, and the $\mathrm{TiO}_{2}$ median size was $0.3 \mu \mathrm{m}$ (90\% less than $1 \mu \mathrm{m})$.

\section{DISCUSSION}

Public and workforce anxiety may be generated by speculation, sometimes uninformed, about hazards from industrial processes or operations. Indeed, such scares are commonplace and often welcomed by the news media. In most instances, facts are hard to come by and evidence of adverse human health effects is not available. How should an organisation or a regulatory authority respond to such anxieties?

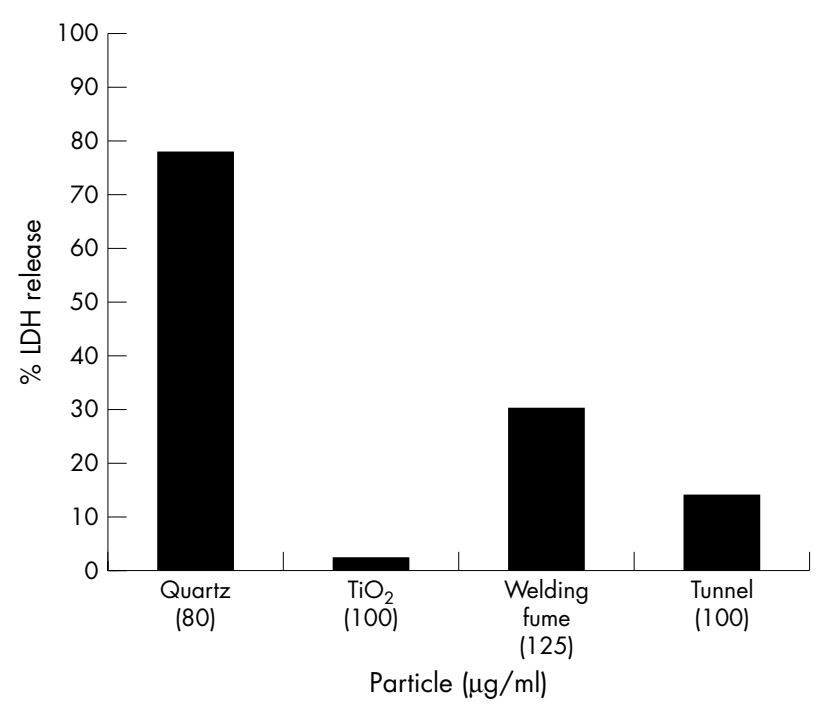

Figure 8 Percentage release of LDH following treatment with the indicated doses of different particles.

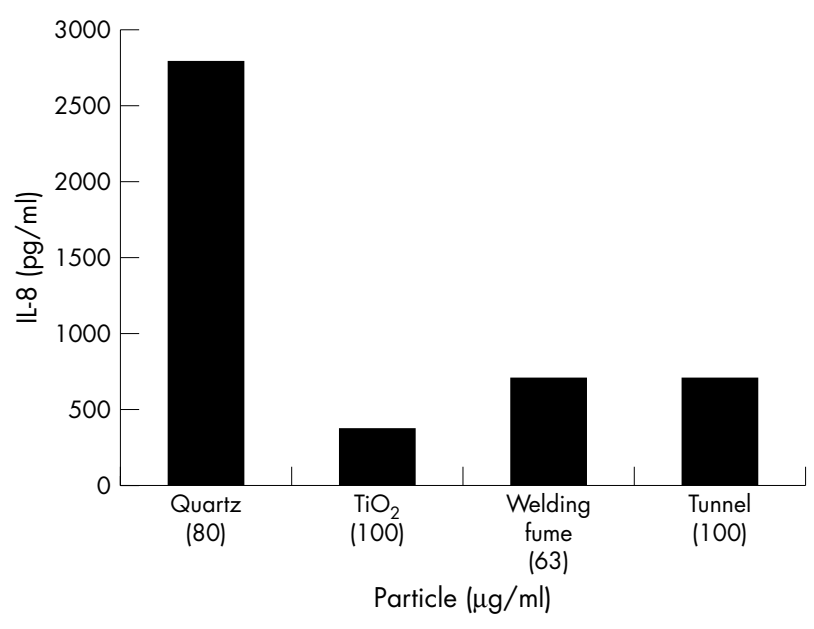

Figure 9 Release of IL-8 following treatment with the indicated doses of different particles.
In developing a response it is useful to have well informed estimates of the risks. This depends on an understanding of the toxic hazard, usually based on toxicological studies at relatively high dose, the likelihood and intensity of human exposure, and if possible information on relationships in populations between exposure to the material in question and adverse health effects. There is a rational, four pronged approach to obtaining such estimates, and a piecemeal response usually leads only to further confusion and exacerbation of anxieties. The basis of this approach is to attempt to answer a series of questions, each of which may lead to or negate the need for the next, as follows:

- What are people exposed to?

- What are the toxic effects of this agent (i.e. its hazard)?

- How much are people exposed to?

- What associations have previously been shown in populations exposed to this agent (i.e. the risk)?

It is often possible to estimate risks reliably with such an approach, but if the fourth question cannot be answered it may be necessary to carry out an appropriate epidemiological study, if a study of suitable power and reliability can be designed and conducted.

In the present case we argued, from some prior understanding of possible answers to the first two questions, that a careful assessment of exposures would allow us to make some estimates of risk relative to that of other workers exposed to similar substances. We speculated, correctly as it turned out, that underground exposures would be mainly to particulate iron oxide and that the concentrations of ultrafine, combustion generated particles would be lower than above ground. We did not know what levels of exposure might obtain underground, nor did we have any knowledge of the toxicity of such dust, although we had previously studied welding fume and many other industrial and environmental dusts of varying toxicity. We presented our proposals to those primarily concerned, the managers and workers of the London Underground, and in discussion with them agreed the methods to be used. We left open the possibility of later epidemiological studies if our results suggested a need for them.

\section{What are people exposed to?}

The answer to this question is that people underground are exposed to iron oxide, assuming the fine iron abrasion dust is rapidly oxidised, with trace amounts of chromium, copper, zinc, manganese, and quartz. There is insufficient quartz to cause silicosis, and earlier studies carried out when somewhat higher levels had been present had shown that the toxicological effects of quartz were ameliorated by the iron oxide. ${ }^{17}$ The concentrations of chromium and manganese would be less than one tenth and one hundredth respectively of the occupational exposure standards for these metals in the most highly exposed workers. At the same time, concentrations of ultrafine particles are lower underground, illustrating the fallacy of quoting risks based on mass measurements of dusts from different sources. The well known associations between outdoor air pollution and illness relate to exposure to dust generated by fossil fuel combustion comprising mainly extremely small particles weighing very little. In the Underground the particles are larger and heavier, and made of iron rather than carbon. It is highly unlikely that such aerosols would have similar effects on people. On that basis, we judged that it is inappropriate to estimate the risks to workers and commuters underground by assuming that risks per $\mu \mathrm{g} / \mathrm{m}^{3} \mathrm{PM}_{2.5}$ (or $\mathrm{PM}_{10}$ ) are similar in the two situations. Such comparisons would be misleading. 


\section{What are the toxic effects of the substance to which they are exposed?}

In addressing this question we carried out three standard tests of toxicity. We had only limited amounts of LU dust and even less $\mathrm{PM}_{2.5}$ from London, and so we were limited in the tests that we could do. Moreover, our recent studies have shown that $\mathrm{PM}_{10}$ is an unsatisfactory comparator, in that its in vitro toxicity varies greatly from day to day, depending on local and trans-boundary sources, as well as from place to place. ${ }^{18}$ We therefore compared our results with those from well characterised control dusts-titanium dioxide, welding fume, and quartz, in increasing order of toxicity. This showed that, weight-for-weight, underground dust is comparable in toxicity to welding fume, more than titanium dioxide and appreciably less than quartz. An important point to recognise is that the concentration at which toxicity appears in these simple in vitro tests is very high, some 40000 times that which would reach the central alveolar region of the lung of someone working underground. ${ }^{19}$

It has been suggested that the toxicity of many inhaled particles, including ambient particulate matter, is due in part to its iron content, ${ }^{13}$ and that therefore a dust comprising iron must be exceptionally toxic. However, the toxicity of such particles is due in large part to free iron ions on the surface, available to take part in Fenton chemistry and to generate free radicals. ${ }^{13}$ This was the case in this study, where chelation of the free iron removed the toxicity. In other words, the similarity to welding fume comes from the surface iron, which is a very small proportion of the total. But molecular iron is also toxic when absorbed into the body, and the gut has sophisticated mechanisms for preventing absorption of more than the $1-2 \mathrm{mg}$ required daily. Absorption of iron from the lungs is fortunately prevented by the existence of a similar mechanism that ensures its uptake by macrophages, ${ }^{20}$ and this is presumably the reason that haemochromatosis has rarely been described in welders, ${ }^{21}$ who may be exposed to between 1 and $5 \mathrm{mg}$ per shift. Where it has, it is likely that the individual is at risk because of a genetic polymorphism, which presumably influences lung as well as gut uptake. The approximate maximal dose of iron to the lung of an LU worker, assuming a respired volume of $4 \mathrm{~m}^{3}$ per shift, $50 \%$ deposition at alveolar level, and molecular iron (as opposed to iron oxide) to comprise $50 \%$ of the dust inhaled would be less than $50 \mu \mathrm{g}$ daily at alveolar level, most of which is likely to be removed by the above mechanisms. The normal daily iron requirement is $1 \mathrm{mg}$ in men and double or more in menstruating women.
How much are people exposed to?

The answer to the third question allows a perspective on the more alarmist speculations. ${ }^{7}$ Workers exposed underground would receive a maximum of $200 \mu \mathrm{g} / \mathrm{m}^{3}$ over eight hours. The UK occupational exposure standard for welding fume (measured as iron oxide) is $5 \mathrm{mg} / \mathrm{m}^{3}\left(5000 \mu \mathrm{g} / \mathrm{m}^{3}\right)$ over an eight hour shift. The limit is identical to that of iron oxide (measured as iron). Welding fume comprises significantly finer particles than those found in the Underground (fig 10). Commuters exposed for two hours would receive an incremental $\mathrm{PM}_{2.5}$ exposure of $17 \mu \mathrm{g} / \mathrm{m}^{3}$ over 24 hours, but this would comprise iron oxide rather than ultrafine particles.

\section{What associations have previously been shown in populations exposed to this substance?}

The final question is most readily answered by considering studies of welders, of which there are many. Welding fume is undoubtedly toxic, although risks to welders other than that of pneumonia ${ }^{22}$ are generally attributed to components of the fume other than iron. The maximum exposures in LU are approximately 25-fold lower than the UK occupational exposure standard for iron oxide and welding fume. A fume is likely to be more toxic than an abrasion generated dust, since it is finer and so presents a much greater surface area per unit mass to the lungs, leading to more rapid dissolution of soluble toxics such as metals as well as presenting a greater surface area for free radical reactions if the surface is inert. ${ }^{23}$ We concluded that risks of serious disease of the lungs or heart from exposure underground would be very low, and probably difficult to detect above background in any feasible study. Thus a sensible answer to the question "Should I travel by London Underground?" would be: "If you travel in London, base your choice on cost and convenience, not on risks to health by inhalation of dust. Above ground you will breathe traffic fumes, below ground less of that, but some iron oxide." We did not recommend a direct epidemiological study as we believed that any small risks that might be present would be difficult or impossible to detect in any practicable study. This was accepted by the LU management and union representatives.

In conclusion, we obtained sufficient information on likely exposures to suggest that those principally at risk from dust inhalation by working or travelling in the London Underground should not be seriously concerned, although efforts to reduce dust concentrations should continue, since the dust is not without toxicity. In doing so we used a methodology that could be considered at an early stage for
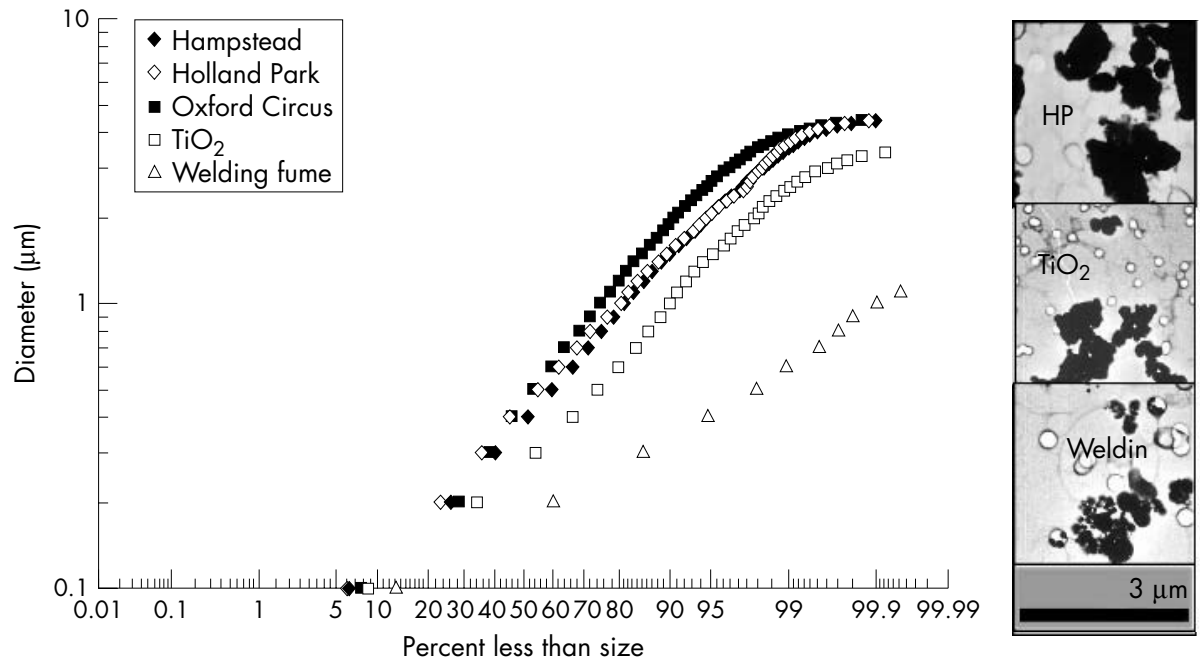

Figure 10 Log probability plot comparing the tunnel dust size distributions with the data for the control dusts, plus photomicrographs. 
investigation of other similar health alerts, for providing information in place of speculation.

\section{ACKNOWLEDGEMENTS}

We acknowledge London Underground Limited for funding and the LUL Dust Action Group for helpful discussions and guidance in the design of the study. Dr Olivia Carlton and Chris Beach facilitated the dust sampling and gave useful advice on the background to the study. Geoff Beaumont at IOM developed and tested the high volume $\mathrm{PM}_{2.5}$ sampler used in the study. Andrew Apsley, Karen Creely (IOM), and Dr Smita Dick (Aberdeen) did the dust sampling. Laurie Davies and Steve Clark at IOM undertook subsequent laboratory characterisation of the dusts. Dr Al Jimenez at ELEGI Colt Laboratory and Prof Paul Borm of Dusseldorf University worked on the toxicity tests. The quartz data were obtained by Miss Claire Monteiller (IL-8) and Miss Kirsty Sherriffs (LDH), while the LDH and IL-8 data for welding fume were obtained by Miss Jane McNeilly.

We are grateful to Dr Vicki Stone from Napier University for the ambient PM dusts and to Dr David Mark from the Health and Safety Laboratory for the loan of sampling equipment. Profs Bob Maynard and Jon Ayres provided useful comments on the work.

\section{Authors' affiliations}

A Seaton, J Cherrie, J F Hurley, C L Tran, Institute of Occupational

Medicine, Edinburgh, UK

M Dennekamp, Department of Environmental and Occupational

Medicine, Aberdeen University

K Donaldson, ELEGI Laboratory, Edinburgh University

Competing interests: none declared

\section{REFERENCES}

1 Pfeifer GD, Harrison RM, Lynan DR. Personal exposure to airborne metals in London taxi drivers and office workers in 1995 and 1996. Sci Total Environ 1999;235:253-60.

2 Adams HS, Nieuwenhuiijsen MJ, Colvile RN, et al. Fine particle (PM2.5) exposure levels in transport microenvironments, London UK. Sci Total Environ 2001;279:29-44

3 Johansson C, Johansson PA. Particulate matter in the underground of Stockholm. Atmos Environ 2002;37:3-9

4 Chillrud SN, Epstein D, Ross JM, et al. Elevated airborne exposures of teenagers to manganese, chromium and iron from steel dust and New York's subway system. Environ Sci Technol 2004;38:732-7.

5 Health and Safety Executive. Dust in the London Underground. London: HMSO, 1982.
6 Priest D, Burns G, Gorbunov B. Dust levels on the London Underground: a health hazard to commuters? 1998. http://62.164.135.147/feat/ feat0017.htm

7 Britton M. Lifestyle and your lungs. Lung Report III. British Lung Foundation, 2003.

8 Health and Safety Executive. Quartz in respirable airborne dusts. Laboratory method using infra-red spectroscopy (direct method). MDHS 37, 1987.

9 Occupational Safety and Health Administration. Metal and metalloid particulate in workplace atmospheres. Method ID121. Washington: OSHA, 1991. http://www.osha.gov/dts/sltc/methods/inorganic/id121/ id121. html.

10 Committee on Medical Effects of Air Pollution. Non-biological particles and health. London: $\mathrm{HMSO}, 1995$

11 Lieber MB, Smith B, Szakal A, et al. Continuous tumor-cell line from a human lung carcinoma with properties of type II alveolar epithelial cells. Int J Cancer 1976;17:62-70.

12 Driscoll KE. Macrophage inflammatory proteins-biology and role in pulmonary inflammation. Exp Lung Res 1994;20:473-90.

13 Gilmour PS, Brown DM, Lindsay TG, et al. Adverse health effects of PM 10 particles: involvement of iron in generation of hydroxyl radical. Occup Environ Med 1996;53:817-22.

14 Gilmour PS, Rahman I, Donaldson K, et al. Histone acetylation regulates epithelial IL-8 release mediated by oxidative stress from environmental particles. Am J Physiol Lung Cell Mol Physiol 2003;284:L533-40.

15 McNeilly JD, Heal MR, Beverland IJ, et al. Soluble transition metals cause the pro-inflammatory effects of welding fumes in vitro. Toxicol Appl Pharmacol 2004;196:95-107.

16 Gilmour PS, Beswick PH, Brown DM, et al. Detection of surface free radical activity of respirable industrial fibres using supercoiled phi X174 RF1 plasmid DNA. Carcinogenesis 1995;16:2973-9.

17 Cullen RT, Addison J, Brown GM, et al. Experimental studies on dust in the London Underground, with special reference to the effects of iron on the toxicity of quartz. IOM Report TM/95/01. Edinburgh: Institute of Occupational Medicine, 1995

18 Schins RP, Lightbody JH, Borm PJ, et al. Inflammatory effects of coarse and fine particulate matter in relation to chemical and biological constituents. Toxicol Appl Pharmacol 2004; 195:1-11.

19 Hurley F, Cherrie J, Donaldson K, et al. Assessment of health effects of long-term exposure to tunnel dust in the London Underground. IOM Report TM/02/04, appendix 2. Edinburgh: Institute of Occupational Medicine, 2004.

20 Ghio AJ, Carter JD, Richards JH, et al. Disruption of normal iron homeostasis after bronchial instillation of an iron-containing particle. Am J Physiol (Lung Cell Mol Physiol 18) 1998;274:L396-403.

21 Doherty MJ, Healy M, Richardson SG, et al. Total body iron overload in welder's siderosis. Occup Environ Med 2004;61:82-5.

22 Palmer KT, Poole J, Ayres JG, et al. Exposure to metal fume and infectious pneumonia. Am J Epidemiol 2003;157:227-33.

23 Duffin R, Clouter A, Brown DM, et al. The importance of surface area and specific reactivity in the acute pulmonary inflammatory response to particles. Ann Occup Hyg 2002;46(suppl 1):242-5.

(1) a, c; (2) b; (3) d; (4) c; (5) d 